\title{
Leucemia de células dendríticas en pediatría apropósito de un caso
}

Dra. Quimi Ortiz Ivonne

Ivonnes_12386@yahoo.es

Dr. Briones Macías Carlos Enrique

Carlos_briones_05@hotmail.com

Dra. Preciado Cabezas Luz Esnedi

luespreca@hotmail.com

Dr. Luimer Gómez

Médico Oncólogo pediatra

Hospital Dr Francisco Icaza Bustamante

Guayaquil - Ecuador

\section{RESUMEN}

Presentamos el caso de una niña sin asociación a algún desencadenante o patología, que ingresa al Hospital Dr. Francisco Icaza Bustamante. Por presentar lesiones dérmicas multilobuladas violáceas Paciente llega al Hospital hemodinàmicamente estable, se procede a realizar estudios de las lesiones dérmicas, los mismos que confirman el diagnóstico de leucemia de células dendríticas

Pero nos llama la atención, ya que es infrecuente en la edad pediátrica, es común en adultos mayores y la mediana de edad en el momento del diagnóstico es de 65 a 67 años, no se registran casos en niños, es el primer caso en niños reportado en nuestro hospital

Palabras claves: leucemia de células dendríticas; lesiones dérmicas 
Leucemia de células dendríticas...

\title{
Dendritic cell leukemia in pediatrics about a case
}

\begin{abstract}
We present the case of a girl with no association to any trigger or pathology, who is admitted to the Dr.Francisco Icaza Bustamante Hospital. Due to presenting violaceous multilobed the lesions Patient arrives at the hospital hemodynamically stable, studies of the de dermamal lesions are carried out, the same ones that confirm the diagnosis of dendritic cell leukemia.

But it draws our attention,since it is infrequent in pediatric age, it is common in older adults and the median age at the time of diagnosis is 65 to 67 years, there are no cases in children, it is the first case in children reported in our hospital
\end{abstract}

Key words: dendritic cell leukemia; dermal lesions

Artículo recibido: 30 noviembre. 2021 Aceptado para publicación: 29 diciembre 2021 Correspondencia: Ivonnes_12386@yahoo.es Conflictos de Interés: Ninguna que declarar 


\section{INTRODUCCIÒN}

La neoplasia de células dendríticas plasmocitoides blásticas (BPDCN) es una neoplasia maligna hematológica poco frecuente y clínicamente agresiva que se manifiesta con mayor frecuencia como lesiones cutáneas con o sin compromiso de la médula ósea y diseminación leucémica.

La nomenclatura utilizada para describir esta entidad ha evolucionado a lo largo de los años a medida que ha mejorado la comprensión de la biología subyacente. El tumor se describió inicialmente en 1995 como una leucemia agranular aguda de células asesinas naturales (NK) CD4 positivas. En base al aspecto blástico y la expresión de CD56, se utilizó el término "linfoma blástico de células NK". Posteriormente, se acuñó el término "neoplasia/tumor hematodérmico agranular CD4 + CD56 +" basándose en el inmunofenotipo y una predilección por la afectación cutánea. Sin embargo, tras el descubrimiento y la confirmación de que el BPDCN se deriva de las células dendríticas plasmocitoides (células dendríticas de tipo 2), se eligió la nomenclatura actual, neoplasia de células dendríticas plasmocitoides blásticas, para describir la entidad en la clasificación de 2008 de la Organización Mundial de la Salud.

Los BPDCN representan el 0,7\% de los linfomas cutáneos primarios Sin embargo, los registros de linfomas cutáneos probablemente subestiman la verdadera incidencia de BPDCN porque una pequeña pero significativa proporción de pacientes se presentan sin lesiones cutáneas.BPDCN se ha descrito solo 5 casos en niños, es más común en adultos mayores y la mediana de edad en el momento del diagnóstico es de 65 a 67 años. Hay un modesto predominio de hombres a mujeres de aproximadamente 2.5: 1 .

Las células dendríticas plasmocitoides son capaces de producir grandes cantidades de interferones de tipo I (IFN- $\alpha / \beta)$ en respuesta a virus o ácidos nucleicos derivados de virus. Si bien es biológicamente plausible que la exposición viral pueda desempeñar un papel en la patogénesis, hasta la fecha no se ha informado ninguna asociación entre BPDCN y un patógeno viral

Si bien se han informado varias anomalías citogenéticas recurrentes, ninguna es exclusiva de BPDCN. 
Los estudios de hibridación genómica comparativa de matrices (CGH) han informado de la pérdida del número de copias de $\mathrm{ADN}$ genómico para varios genes que afectan la progresión del ciclo celular, incluidos p18, p16, p27 y RB1

Los estudios moleculares también han informado de mutaciones en los genes TET2 y TP53. No se han informado mutaciones de NPM1; por el contrario, las mutaciones FLT3-ITD pueden estar presentes en un subconjunto de pacientes.

Un estudio que utilizó el perfil de expresión génica y la inmunohistoquímica identificó la activación aberrante de la vía NF-kB en estos tumores y exploró la posibilidad de una orientación terapéutica de la vía para tratar el BPDCN.

Dada la rareza de BPDCN, estas observaciones provienen de un número relativamente pequeño de pacientes. Además, no está claro si estas alteraciones genéticas contribuyen a la transformación maligna o si simplemente representan una consecuencia de la transformación maligna.

La mayoría de los pacientes con BPDCN presentan lesiones cutáneas con o sin afectación de la médula ósea y diseminación leucémica. Una minoría de casos se presenta con leucemia sin afectación cutánea. Las lesiones cutáneas pueden ser de color marrón a violetas, como lesiones, placas o tumores, parecidas a hematomas, y pueden ser solitarias o diseminadas. Citopenias, linfadenopatías y / o esplenomegalia están presentes en una mayoría significativa de pacientes. Se ha informado de afectación del hígado y parece ser más frecuente en pacientes con afectación extensa de la médula ósea. También se ha informado de afectación de las amígdalas, cavidades paranasales, pulmones, ojos, sistema nervioso central (SNC) y paravertebral.

\section{DESCRIPCIÒN DEL CASO}

Se trata de una niña de 8 años, quien ingreso al hospital del niño Francisco Icaza Bustamante de Guayaquil, con un cuadro clínico de 14 meses de evolución, caracterizado por una lesión de más o menos 5por $3 \mathrm{~cm}$ multilobulada dura de bordes irregulares violácea, no dolorosa, localizada en antebrazo derecho, Fig 1 sin causa aparente y sin síntomas acompañantes. Al examen físico no se palpa adenomegalias, sin hepatomegalia, sin esplenomegalia, en el hemograma se encontró leucocitos 6.700, neutrófilos \% 51.10, VAN 3423, linfocitos \% 30.80, monocitos \% 9.70, Hb 12,6 g/dl, Hcto 36,90 \%, plaquetas 510.00, LDH 257, TP 19,3 TTP 40. 
Figura $\mathbf{N}^{\circ} \mathbf{1}$ Lesiones cutáneas multilobuladas

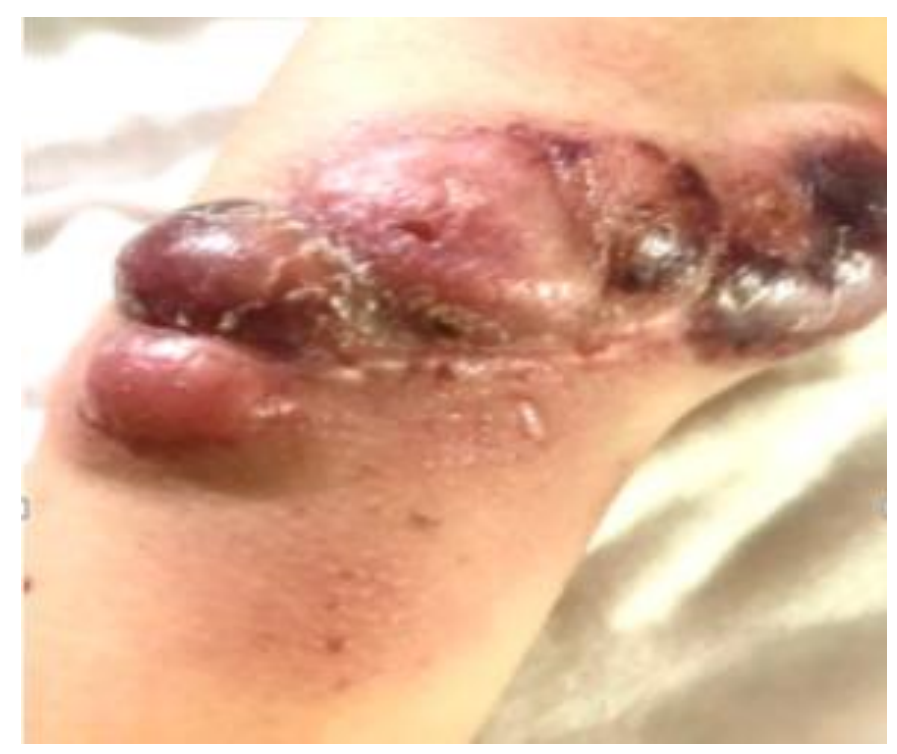

La radiografía de tórax fue normal, TAC de cerebro, tórax y abdomen fueron normales PET/CT se evidencio afectación tumoral extra-nodal cutánea/subcutánea en antebrazo.

La citometrìa de flujo en $\mathrm{MO}$ reporto fenotipo compatible con células patológicas del $(80,65 \%)$ que expresan CD 123++, HLADR++, NG2 ++, CD56++,CD4++, CD304++,CD36++,lo que sugiere neoplasia de células blàsticas dendríticas plasmocitoides. Fig2. El estudio de inmunohistoquimica revelo positividad para CD56, CD4, CD43, CD99. Fig 3

Se considerò el diagnostico de leucemia de células blasticas dendríticas plasmocitoides, con compromiso cutáneo, y se decidió iniciar quimioterapia, durante su tratamiento recibió polioquimioterapia, ultimo protocolo que recibió PROTOCOLO FRALLE 2000 grupo b2.

\section{Figura $\mathbf{N}^{\circ} 2$ Citometria de Flujo de Mèdula Òsea}

\section{EENOTIPOINMUNOLOGICO DELAS CELULAS PATOLOGICAS}

Expresan CD45+hom, HLADR+*, NG2t+hom, CD56+*hom, CD36*thet, CD123t+hom, CD7+thom, CD304+thom, CD2? $*$ het, CD117*+het, CD22+deb, CD15*- het, CD33-deb, CD38-deb, CD14*; negativo a CD34, MPO-, CD19- CD13-, CD16-,

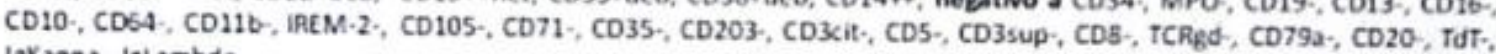
lgKappa , letambda

\section{COMENTARIO}

Se observa en la muestra de medula ósea la presencia de un $80,65 \%$ de celulas neoplasicas que expresan (CD4Stdeb, CD56r+

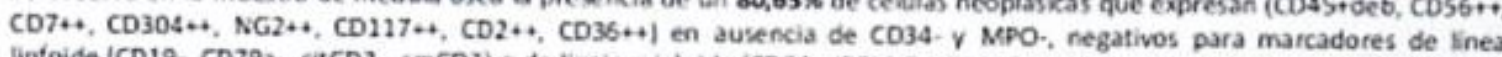
linfoide (CD19-, CD79a-, citCD3-, smCD3) o de linaje mieloide (CD64-, ifEM-2, CD13-), excepto por la expresion de CD15++het $\checkmark \mathrm{CO} 33 \times d e b$

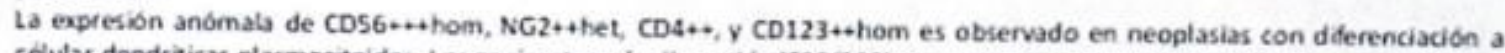
celulas dendriticas plasmocitoides. Los parametros de dispersión (FSC/SCC) muestran celulas patologicas de tamah̆o pequerio a medano, con complejidad interna intermedia.

concuusion:

Fenotipo compatible con CÉLULAS PATOLOGICAS dEL $(80,65 \%)$ QUE EXPRESAN CD123+t, HLADR,++ NG2 $+*$, CDS6 ++ , CD $+*$, CD304++, CD36*t, LO QUE SUGIERE DESCARTAR NE OPLASIA DE CELULAS BLASTICAS DENDRITICAS PLASMOCITOIDES.

La interpretación del presente resultado requiere la correlación de los datos de la historia clinica. mielograma. estudios moleculares, biopsia y otros exalmenes complementarios del paciente. 
Figura $\mathbf{N}^{\circ} 3$ Estudio De Inmunohistoquimica

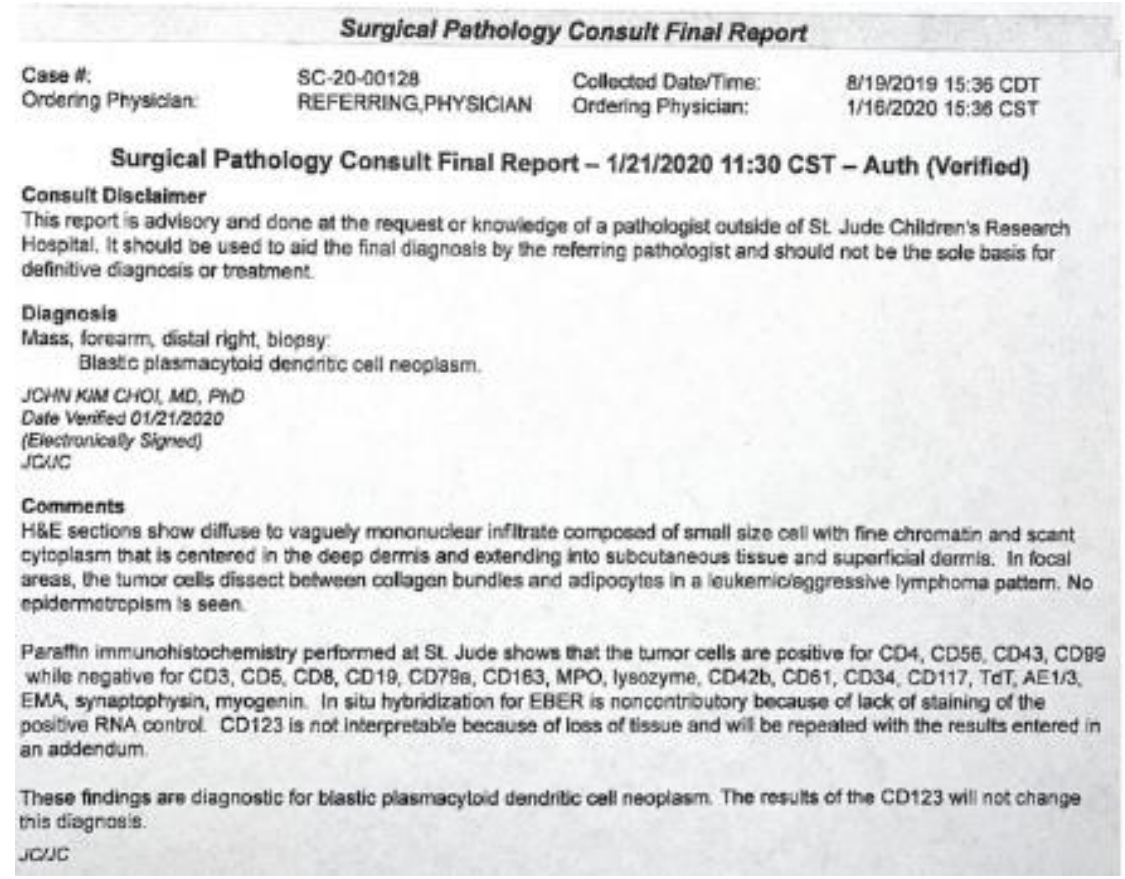

Se realizó evaluación de enfermedad mínima residual la cual reporto muestra de mèdula ósea sin evidencia de blastos mieloides, linfoides ni células dendríticas plamocitoides en 8116326 de eventos analizados. La paciente al momento se encuentra viva en el programa para transplante

\section{DISCUSIÓN}

La leucemia de células dendríticas plasmocitoides blásticas o BPDCN, es una patología hematológica y oncológica muy infrecuente, y más aún en la población infantil con una incidencia extremadamente baja (entre el 0,7 al $1 \%$ de las leucemias agudas y los linfomas cutáneos), muy agresiva, con afectación de la piel hasta en un 90\% de los casos, siendo el principal motivo de consulta. La manifestación clínica es heterogénea, además de tener un perfil de maduración celular variable, con rasgos desde leucemia aguda de células neoplásicas inmaduras hasta rasgos de linfomas periféricos maduros; por lo que esto puede ocasionar errores en el diagnóstico y tratamiento.

La afección cutánea suele ser la primera en manifestarse, principalmente con lesiones de tamaño, forma y color variable, como nódulos, tumoraciones y placas, sobre todo en extremidades, tronco y cara, compatibles con el caso de este paciente.

Puede haber afectación a órganos, linfadenopatías e infiltración a medula ósea presentando pancitopenia, particularmente trombocitopenia, aunque en nuestro caso no se presentó en ese momento. 
La citometría de flujo es esencial en el diagnóstico de BPDCN y en la enfermedad mínima residual. Por la sobreposición de los marcadores con otras leucemias, por lo que se necesita un panel amplio para establecer el diagnóstico de manera correcta.

La expresión elevada de CD123, además de la coexpresión de CD56 y CD4, es casi patognomónica de neoplasia de células blásticas dendríticas plasmocitoides, su disminución resulta en la regulación negativa de CD123 y CD56.

En ocasiones el diagnóstico puede volverse incluso más difícil en ausencia de los marcadores CD4, CD56 o ambos, donde se requiere un manejo multidisciplinario para establecer el diagnóstico, pero en nuestro caso todos estos fenotipos fueron positivos y compatibles para la enfermedad detallada.

El resultado final y prospecto de vida va a depender del tratamiento, la respuesta del organismo a ese tratamiento y de la etapa de la enfermedad en que se inicie. La quimioterapia intratecal está incluida en los protocolos terapéuticos utilizados para las leucemias linfoblásticas agudas, tal como se usó en nuestra paciente detallada en el caso clínico y en sus controles la enfermedad mínima residual esta negativa por lo que se indica trasplante alogénico de médula ósea, siempre que sean pacientes aptos para dicho tratamiento como lo indica algunos autores.

Cabe recalcar que es el primer caso reportado en el Hospital Dr. Francisco Icaza Bustamante de la ciudad de Guayaquil - Ecuador, ya que como indica la literatura, esta patología es más común en adultos mayores y muy infrecuentes en niños.

\section{Consentimiento Informado}

Los autores cuentan con el consentimiento escrito por el Hospital Dr Francisco Icaza Bustamante Guayaquil - Ecuador

\section{REFERENCIAS BIBLIOGRAFICAS}

Cedeño,V (enero 2021). Leucemia de células dendríticas. https://revistas.utm.edu.ec/index.php/QhaliKay/article/view/2747

Sandeep, G (noviembre de 2021). Neoplasia de células dendríticas plasmocitoides blásticas. https://www21.ucsg.edu.ec:2065/contents/blastic-plasmacytoiddendritic-cell-

neoplasm? search=Neoplasia\%20de $\% 20 \mathrm{c} \% \mathrm{C} 3 \%$ A 91 ulas $\% 20 \mathrm{dendr} \% \mathrm{C} 3 \%$ ADtica s\%20plasmocitoides\%20b1\%C3\%A1sticas\&source=search_result\&selectedTitle $=1 \sim 10 \&$ usage_type=default\&display_rank=1 
Contreras,F (3 de diciembre de 2019) Plasmacytoid dendritic blast cell neoplasia. file:///C:/Users/Hp/Downloads/LCD\%20PDF\%201.pdf

Lopera J,(julio del 2013) Leucemia de Células Dendríticas en Pediatria: Primer Caso en Colombia. https://www.cure4kids.org/ums/oncopedia/case_detail/index.php?id=601

Paez A.(agosto del 2013) Leucemia Plasmocitoide de Celulas Dendriticas. A Proposito de un Caso. https://www.cure4kids.org/ums/oncopedia/case_detail/index.php?id=608

Garnache-Ottou F, Feuillard J, Saas P. Plasmacytoid dendritic cell leukaemia/lymphoma:towards a well defined entity? $\mathrm{Br} \mathrm{J}$ Haematol. 2007;136(4):539-48

Lúcio P, Parriera A, Orfao A. CD123hi dendritic cell lymphoma: an unusual case of nonHodgkin lymphoma. Ann Intern Med. 1999;131(7):549-50.

Bayerl MG, Rakozy CK, et al. Blastic natural killer cell lymphoma/leukemia: a report of seven cases. Am J Clin Pathol. 2002;117(1):41-50.

Ng AP, Lade S, Rutherford T, et al. Primary cutaneous CD4+/CD56+ hematodermic neoplasm (blastic NK-cell lymphoma): a report of five cases. Haematologica. 2006;91(1):143-4.

Gopcsa L, Banyai A, Jakab K, et al. Extensive flow cytometric characterization of plasmacytoid dendritic cell leukemia cells. Eur J Haematol. 2005;75(4):346-51.

Nath R, Abo SM. Prolonged survival in an elderly patient with CD4+ CD56+ lymphoma of the skin with autologous peripheral blood stem cell transplantation (PBSCT). ASH Annual Meeting Abstracts. 2005;106(11): 5493.

Wright KD, Onciu MM, Coustan-Smith E et al. Successful treatment of pediatricplasmacytoid dendritic cell tumors with a contemporary regimen for acute lymphoblastic leukemia. Pediatr Blood Cancer. 2013; 60: E38-41.

Nargund AR, Madhumathi DS, Premalatha CS, et al. Accelerated phase of chediakhigashi syndrome mimicking lymphoma--a case report. J Pediatr Hematol Oncol 2010; 32: e223-226.

Sang W, Wang CF, Cheng YF, et al. [Blastic plasmacytoid dendritic cell neoplasm: a clinicopathologic study]. Zhonqhua Bing Li Xue Za Zhi. 2012;41(5):326-30. 
Piña-Oviedo S, Herrera $\mathrm{H}$, Coronado $\mathrm{H}$, Del Valle $\mathrm{L}$, Ortiz-Hidalgo $\mathrm{C}$. CD4+/CD56+hematodermic neoplasm: presentation of 2 cases and review of the concept ofan uncommon tumor originated in plasmacytoid dendritic cells expressing CD123 (IL-3 receptor alpha). Appl Immunohistochem Mol Morphol.2007;15(4):481-6.

Rojas C, Jimenez L, Paz V, Vermiglio R, Acosta M, Chacin L. Leucemia de células dendríticas a propósito de un caso. Rev VeneZ de Oncol. 2010; 22 (4):260-264.

Hansfor JR, Kotecha RS, Jevon G, Cole CH, Gottardo NG. Efficacy of acute myeloid leukemia therapy without stem-cell transplantation in a child with blastic plasmacytoid dendritic cell neoplasm. Haematologica. 2013;98(3):e30-1.

Vilcahuamán V, Quinto N, Pacheco M, Paredes A, Gadwyn ,Carbajal T. Neoplasia blástica plasmocitoide de células dendríticas. Folia dermatol. Peru 2010; 21 (3): 151-156. 